\title{
LA INTELIGENCIA MORAL Y LA RAZÓN ETICA
}

1. "Conocer" y "entender". La "inteligencia" tiene, como objeto propio interior, la presencia del ser o la luz de la verdad, madre de todas las demás verdades; pero es inteligencia de un sujeto y por tanto encarnada, constituyendo con él una unión sustancial. El sentir pone a los vivientes en contacto entre sí: esta relación de vida, por la vía de la razón se eleva en el hombre al grado de conocimiento. La inteligencia es intuición de la ley que es la intuición misma del ser, la verdad primaria que vuelve verdadero todo juicio moral formulado por la razón; pero es la voluntad la fuerza que estimula a la razón a juzgar lo que ella quiere. Sin embargo, la voluntad, que es siempre voluntad de un yo o de un ente real, no quiere en abstracto; quiere o lo que la razón conoce (y lo conoce a través de los sentidos) o lo que capta inmediatamente. Lo que quiere lo desea o lo ama; pero desea y ama un ente, una cosa, otro yo (el tú); amarlo es vivirlo, penetrarlo, que es más y, diré, mejor que comprenderlo. En efecto, comprenderlo es encerrarlo en un juicio, "definirlo" por aquello que es: penetrarlo, en cambio, es abrirlo, a través del juicio, a la actualización del valor que él es, a fin de que sea cada vez más persona, esto es, captarlo más allá del puro ligamen cognoscitivo, en su aspiración al deber ser, en que reside su inteligibilidad última y suprema. "Quererlo" es no sólo reconocerlo por lo que es (uniformidad de la voluntad con la razón), sino amarlo, esto es, promoverlo, algo como anticiparlo en su deber ser, ayudarlo a ser su futuro, toda la perfección potencial; en definitiva, abrirlo a su porvenir y no encerrarlo en el presente. Es en este punto donde la razón, la inteligencia y la voluntad se encuentran, armonizan y colaboran: la intuición intelectual hace que el juicio sea verdadero en la verdad del ser y la razón que juzga no se pierda en lo abstracto, sino que se adhiera al ser real, en el cual la voluntad ama al ser. La razón conoce lo que es a la luz del ser, que ningún qui o quid real puede èxistenciar en toda su infinitud; la voluntad realiza la unión viviente con el ser conocido presentado por la razón a la luz del ser, para la cual es la verdad un bien y es el bien una verdad. La voluntad es la causa eficiente y motriz, cuyo fin es el bien deseado como se lo presenta la razón, pero como todo bien existente es finito y no agota la infinitud de la verdad o del bien (el ser) como está presente a la inteligencia, se sigue que la unión entre el sujeto que quiere y el bien querido queda siempre abierta a una ulterior unión con un bien menos inadecuado. Por otra parte, este adelantarse la aspiración a querer, que es aspiración a amar, impidiendo a la voluntad darse por satisfecha e incitándola a no agotar [ 250 ] 
su amor, plantea el problema de la inteligibilidad última no sólo de todo querer particular, sino del querer en cuanto tal, de la moral misma. Esto es: ¿cuál es la última salida? ¿Hacia qué vértice se abre y, con ella, el hombre?

De todo problema (y por tanto de toda forma de actividad espiritual) hay razón e inteligencia: la razón tiene el conocimiento, la inteligencia la inteligibilidad. Hay razón del obrar humano, que es el conocimiento de los hechos históricos, el tejido de los acontecimientos, comprobados, construidos, valorados. Pero el problema de la historia no está agotado con ello, antes bien la historia, en el conjunto de sus acontecimientos como de cada acontecimiento singular, también de aquellos que el tiempo cancela y que no son "históricos" a pesar de haber acontecido, como problema del sentido de la historia, de su verdad o de su por qué y de su fin último, empieza donde el conocimiento de los hechos se detiene y se presenta como problema de la inteligibilidad de éstos; y es el verdadero problema filosófico o metafísico de la historia, que se identifica con el problema del sentido y del destino del hombre, de los hombres singulares. Del mismo modo hay la "razón" o el conocimiento de las cosas y está dada, en su parcialidad irreparable, por las ciencias llamadas naturales; $y$ hay la inteligencia de las cosas mismas, que es el problema del existir del mundo y de todo su ser, de la verdad o del por qué y del fin de cada cosa; y es un problema filosófico o metafísico, esto es; de la inteligibilidad de la naturaleza. Y así sucesivamente. "Razón histórica" no es todavía "inteligencia histórica"; el problema de la historia encuentrà su solución adecuada cuando la primera se ilumina en la segunda, cuando las infinitas lucecitas que son las "razones" de los acontecimientos. brillan al rayo potente del único principio de inteligibilidad que hace de un golpe penetrar y abrazar el sentido de la humanidad pasada, presente y futura. En el mismo sentido, "razón ética" no es todavía "inteligencia moral", en cuanto que hay un problema de la moral como conocimiento del bien y del mal, ciencia de las virtudes, etc.; pero hay también el problema del principio supremo de la moral y de su fin último; y es problema de inteligibilidad, coincidente con el sentido de la vida humana. Y entonces la moral encuentra la claridad y la trasparencia de sí misma para sí misma en el tender a la solución del problema que es ella misma, más allá de la "razón ética", en la inteligibilidad de su principio que es constitutivo de su esencia, vida inagotable que la alimenta, aguijón provocador y renovador, el deber ser del deber ser.

Adviértase que el problema de la inteligibilidad no comparece en último término, sino que es el primero y manda y estimula, aunque sea implícitamente, al de la "razón" o del conocimiento. No sólo esto: aquél puede cabalgar más que este último, adelantársele, por lo cual puede haber ( $\mathrm{y}$ hay) inteligencia de la historia aun ignorando todos los acontecimientos históricos, como puede haber ( $y$ hay) inteligencia moral aun ignorando las virtudes, que quedan resueltas en ella y potenciadas. Viceversa, puede haber "conocimien- 
to histórico", y el más vasto, sin inteligencia de la historia (se conoce de la humanidad todo sin saber nada), como puede haber conocimiento y práctica de virtudes sin inteligencia moral y entonces se es virtuoso sin moral: el estar acostumbrado a las buenas costumbres, que es sociabilidad, corrección, licitud pura y simple, norma de conducta, etc. En cambio, la inteligencia moral es presencia, intuición primaria de la ley, que irradia sobre toda la experiencia humana en sus más humildes detalles e inviste, en su cabal potencia, todos los actos de un hombre, hasta el punto de hacerle captar las formas esenciales de los seres, cada uno en su orden y en su grado de ser, sin errar, en una intuición totalitaria y posesiva del sentido supremo de la moral. Por tanto, la inteligencia implica una extensión que va más allá de las costumbres, de las virtudes, de las funciones sociales y de nuestras obligaciones parciales, todas insuficientemente comprensivas y ninguna exhaustiva; va más allá de toda acción moral, que sólo por presunción puede considerarse realizadora de todas las capacidades y de la aspiración íntegra e intacta del espíritu y que sólo la humildad o la modestia de valorarla en su invencible inadecuación hacen que sea verdaderamente moral.

2. "Razón ética" $e$ "inteligencia moral". La razón ética es la "ciencia", no la "sapiencia" de la vida: la sabiduría no es solamente racionalidad; y si es sólo esto, es cálculo, dosificación, mediocridad, algo como una técnica, el "conocer cómo se hace", como si se tratase de un dispositivo o de un engranaje. Es la preceptiva, el manual de moral práctica; es la ética del "te enseño cómo se hace". La razón ética es práctica y programática; elabora planes y programas según sus reglas, teje relaciones, conceptualiza. Pretende ponerle los carriles a la voluntad de modo que tenga el camino marcado y preestablecido. Es ilusión o error creer que un orden semejante sea el orden moral; al contrario, la voluntad moral está por encima de lo prescrito y lo preestablecido, de lo calculado y lo dosificado, de todo el instrumental nocional de la razón, justo porque es voluntad moral, esto es, obediente a la norma, que no es cálculo ni carril, aunque sea itinerario. No es la norma quien reside en la razón, que en tal caso sería la norma de la norma, sino que es la razón quien reside en la norma, que es sólo norma para sí misma, medida de la razón sin ser medida por ella.

La de la razón es la ética menor o inferior; la de la inteligencia, la ética mayor o superior: la primera es la ética de las virtudes, que por sí solas no son todavía virtudes morales; la otra es la moral del amor, donde toda virtud es virtud; es también la moral de la verdad, porque nada es más interior al hombre que la verdad, en cuanto que nada le es más interior que su inteligencia objetiva, que es intuición del ser y por ello también conciencia de su ser, autoconciencia en la riqueza de todas sus formas. Y nada debe el hombre amar más que la verdad. Veritas chari- 
tatis y charitas veritatis. El hombre puede abandonar las virtudes, pero no puede extirpar de sí la verdad, aunque desvaríe (como el loco) o no tenga capacidad de razonar (como el idiota). Nadie puede hacer que se desvanezca en él la presencia de Dios; y por ello, aunque no sea virtuoso, ya por imposibilidad, ya por deliberada voluntad suya, debe ser siempre respetado y amado por lo divino que hay en él, esto es, en cuanto hombre o sujeto dotado de alma pensante, que amo etiam in latronibus, porque "me es siempre lícito amar en cualquiera la inteligencia, aun detestando a aquel que usa mal aquello que amo". 1 Y con nosotros lo ama también Dios, que jamás lo abandona y que vive también en un montón de harapos, al borde de un camino o en la inmundicia de un lupanar, dondequiera que hay un hombre, virtuoso o pecador. Cuando todos nos condenan con las buenas razones de una razón sin bondad, cuando todo nos deja, incluso la razón, la verdad sigue siempre en nosotros y por eso no nos abandona Dios, que está siempre a la espera de un pecio, que es siempre un hombre.

La razón ética es posesiva; la voluntad es, en este caso, voluntad de posesión; quiere para poseer y por eso acaba por tratar también a las personas como cosas, esto es, como medio y no como fin. Las virtudes según la razón ética son también ellas virtudes de posesión: tener para sí o "poseer" la templanza, la prudencia, etc. Así entendidas, no son virtudes, sino splendida vitia; es el egoísmo que se sublima en la virtud, de la que tiene la ambición y también el capricho o las "maneras": es la virtud sin el "estilo" de la virtud; la virtud que desprecia a los demás o los ignora (estoicismo, por ejemplo), virtud sin humildad ni amor, sin pobreza de espíritu. Cuando la voluntad tiene por fin la adquisición de la virtud para poseerla, ya no es moral, sino voluntad ética, que es aspiración a la autosuficiencia, al dominio de sí mismo y de todas las cosas, a la soberbia: su deber ser es la "ciencia" de los demonios, que es justo la ciencia sin amor y sin humildad. En este sentido prefiero al pecador o al culpable que se reconoce tal, humildemente; que sabe arrepentirse, aunque después carezca de la fuerza para no recaer en la culpa; prefiero incluso al que, pecador o culpable, protesta y confiesa su pecado diciendo al mismo tiempo que continuará pecando o que encuentra difícultad para redimirse: hay siempre algo que esperar de él. Prefiero Baudelaire a Kant.

Como posesiva, la razón es inmanentista: sólo aspira a "comprender", esto es, a encerrar dentro de sí, a conocer solamente aquello que puede conceptualizar, esto es, que puede, digámoslo así, "entrar" dentro de sus límites, justo en forma de "comprenderlo" sin ser comprendida por ello; aquella que puede "chupar" en una definición y "poner en forma". La voluntad, guiada por la razón, acaba por uniformarse, por querer sólo lo que la razón comprende, esto es, por realizar un orden práctico o de eticidad inmanente y sólo in-

I San Agustín, Soliloquia, 1. II, c. II. 
manente, cuyo fin es el hombre mismo, para realizarlo en su totalidad que es siempre finitud, que, cumplida, implica la autosuficiencia y el pleno dominio de sí mismo, la autonomía incondicionada. La voluntad, como capacidad de querer hasta el infinito, queda restringida, reducida a los límites de lo finito, de las cosas; y así, ya sin alas, no se levanta de la tierra y cree que la tierra es su. fin último; en definitiva, se pone por fin a sí misma. En tal caso la voluntad asume para sí la norma de la razón ética, que es norma para este mundo, para un fin inmanente al mundo mismo y realizable en él con la pretensión de actualizar plenamente el destino del hombre en este mundo y con medios humanos, al contrario que la inteligencia, que, luz de verdad y por ello infinita posibilidad de pensar, por su naturaleza y por su interior dinamismo empuja al hombre a sobrapasarse, a la razón a verificar su "conocer" en el "saber", su "comprender" en el "ser comprendida"; en contra de la voluntad moral, que es infinita capacidad de querer y así, por su naturaleza y por su movimiento interno, empuja a querer por encima de toda volición particular, estimulada por aquella voluntad primera y última que es la voluntas voluntatum, la voluntad de todas las voluntades y por eso la que mueve la dialéctica misma del querer y de todo querer.

La razón ética se dice aún "humanista", la sola "humanista", justo porque es inmanentista; al contrario, es simplemente anti-humana, porque es negación de la verdad del hombre, de su inteligibilidad profunda, que es también su voluntad profunda, primera y última, condicionante de todas las demás sin estar condicionada por ninguna.

Para ella, en efecto, todo existe en función del hombre y de los fines inmanentes a su duración histórica. En ella es el hombre el centro y existe todo en función de él, que es fin para sí mismo. Este centro, desde el cual se expande todo y al cual retorna todo, en el doble movimiento de él a la periferia y de la periferia a él, se adecúa el todo inmanente de la naturaleza y de la historia y en este todo se adecúa a sí mismo y se cumple. Basta: el hombre, amo del mundo, es su esclavo; en la tentativa de rescatarse y cumplirse en la sola acción histórica, se pierde en ella, sin escape. .La historicidad, que es fundamento y fin de sí para sí misma, es irremediablemente historicismo. Todo para el hombre y el hombre para sí mismo, significa: el hombre es para la naturaleza y la naturaleza lo sujeta y ahoga. ¿Cómo? Adecuándolo a sí, que es deformarlo, hacerlo salir de su propia naturaleza, que es la indomable inadecuación del hombre a la naturaleza. Pero el hombre que encuentra, en contra de su naturaleza, la adecuación en la naturaleza, por esto mismo está fuera de su ser, fuera del orden y por ende fuera de la moral. Y fuera de la moral está lo útil, el placer, el capricho, la comodidad, lo material. El equilibrio normal (y en este caso anormal) se consigue al nivel de la norma de lo útil y del placer, elevados a sistema de vida y a fin del vivir.

De ello se sigue todavía una confirmación de cuanto habíamos dicho 
otras veces: la razón ética es magnificante; magnifica, por ejemplo, la sensación (hedonismo), sutilizada y elevada a fin de la vida y a norma de sabiduría; un valor, cualquiera que sea (la misma razón o la libertad mal entendida como en Kant), etc. Es la venganza de la inteligencia moral; el dinamismo prepotente e indomable del espíritu irrumpe, escapándose de la compresión del "comprender" de la razón que mide con medida absoluta, y se lanza indómito al infinito. Esta rotura de la camisa de fuerza del inmanentismo (que es el esfuerzo, al que está sujeto también el inmanentista, por recuperar en el hombre su naturaleza profunda), compele a la razón, para guardar el punto de honor de la inmanencia, a crearse un ídolo, a elevarlo al rango de absoluto, de modo que la infinitud del espíritu encuentre su adecuación superhistórica y ficticia en algo finito magnificado. "Superstición", en cuanto es superstición atribuir a un ente o a un acontecimiento una potencia que no tiene. Si me ocurre una desgracia y la atribuyo al hecho de que un gato negro atravesó la calle poco antes que yo, es evidente que atribuyo al gato una fuerza o una capacidad que no le pertenece: lo he magnificado, me he hecho de él un ídolo. La magnificación es una extrapolación de los límites y de las funciones de la razón: buscar la adecuación, legítima y verdadera no sólo de las formas finitas en los entes reales de las cuales son propias, sino también la adecuación de la infinidad del ser pensado en un ente o en un valor del orden natural y humano. Mas, como el Ser infinito no pertenece a este orden, la razón, bajo el impulso irrefrenable de la inteligencia, magnifica y absolutiza un ente o un valor finito para presentarlo, en contradicción consigo misma (en efecto, si lo "comprendiese" dentro de sus límites, sería algo finito y ya no lo Infinito, "no comprensible" por la razón) como el Ser o el Valor infinito, al que sólo puede adecuarse la capacidad infinita del espíritu. Haciendo esto, la razón ética se condena a sí misma, denuncia ella misma la imposibilidad (la in-humanidad) del inmanentismo o de la autosuficiencia del hombre, en cuanto que ese fin absoluto (motor primero y último de la voluntad), y, en cuanto tal, no histórico y trascendente, en el que ha de encontrarse la plenitud del hombre, no puede ser nada finito, que es "maquillar" el rostro del hombre, creado por Dios, y no presentarlo en su genuinidad de criatura, hecha por el Creador de modo que exista para el Creador mismo. Y así cae pesadamente sobre sus pies la tentativa de la razón de absolutizarse a sí mismo absolutizando lo finito (o algo finito), en cuanto que lo absoluto, "puesto" por la razón, está comprendido por ella y por tanto contenido en ella y no ella en lo absoluto. De aquí nacen las varias éticas de la razón ética, todas magnificantes del hombre, de su autosuficiencia y autonomía, de su ser principio, fin y ley para sí mismo.

Al contrario, la inteligencia es donadora: no quiere poseyendo, sino dando; ama incondicionalmente, de modo que la ley misma se vuelve ejemplo de vida $y$, por ende, viviente en la persona que la encarna y la expresa. Inte- 
ligencia moral es querer a toda persona y toda cosa en su ser y por el Ser: querer que es amar en el orden del ser, esto es, a la luz de verdad que hace al hombre inteligente. Y entonces no se quiere para "tener" la virtud, sino para "ser" virtuosos, no para poseer, sino para dar, para darse, porque el ser es difusivo. De tal modo, ascienden las virtudes al rango de verdaderas virtudes morales: la prudencia deja de ser habilidad táctica y estrategia; la templanza ya no es solamente goce racional y bien calculado del mundo; la justicia no se reduce a la equitativa distribución o al dar a cada uno lo suyo, de modo que también quien dé tenga su buena parte y se la goce en paz; la fortaleza deja de ser el coraje del miedo y la sapiencia adquiere su verdadero significado de sabiduría y no el despotenciado de "saber vivir".

Hemos dicho que la ley, querida hasta el fondo, se vuelve ejemplo de vida. Aquí está el esencial carácter donador de la inteligencia moral: ser ejemplo no es ser virtuoso para sí (para propia satisfacción o complacencia, por orgullo, etc.), sino para los demás, es caminar humildemente en el mundo difundiendo luz y quedando perennemente afligido de cuantas sombras persisten todavía en nosotros. Esta es la virtud suprema: ser virtuosos a fin de que otro lo sea, esto es, hacer don de la propia vida, ponerla al servicio de los demás, no enorgulleciéndose del don (como diciendo: "tengo tanta virtud que puedo ser pródigo de ella"), sino confirmándose en la persuasión sincera de que a nuestra virtud siempre le falta muchísimo y precisamente el darse todavía a fin de que se haga siempre más moral, justo en este darse a los demás, que es el solo enriquecimiento que le es conveniente. De modo que el concepto de virtud, encendido en el principio de la inteligencia moral, presenta una su dialecticidad interna, compleja y también paradójica, un dinamismo en el que sustraer es sumar y multiplicar y sumar es sustraer y anular, hasta tal punto es la aritmética de la moral sui generis y revolucionaria en sus operaciones singularísimas.

En efecto, ser moralmente virtuoso no es mostrarse tal y decir "fíjate qué virtuoso soy": esto es ejemplo de vanidad o de soberbia, también de jactancia o de estupidez. No es mostrarse, es ser virtuoso y basta. Verán las demás y viendo podrán sentir su atractivo o permanecer indiferentes o también burlarse y ofender. No tienen importancia las reacciones psicológicas que la virtud, encarnada y vivida, pueda suscitar en los demás, y no por desprecio a los demás, sino porque lo que debe importar al ejemplo (un hombre virtuoso viviente) es sólo el ejemplo y esto es vivir hasta el fondo el valor moral. Pero vivirlo hasta el fondo significa no preocuparse de ser virtuoso para sí, que es posesión y no don, sino de serlo para el prójimo; pues sólo se es virtuoso cuando se lo es para otros. Así que el ejemplo verdadero es expansivo, es ímpetu, don generoso sin distinciones ni groseras ni sutiles: ser ejemplo para todos y sobre todo para aquellos que más menester han de él. Y entonces si el ejemplo, en sentido moral, es por su naturaleza expansivo, no hay ejemplo 
agotado y cumplido; antes bien, justo en el ser perennemente ejemplo, se hace ejemplo; pero ser ejemplo es serlo para los demás, darse a otras personas, esto es, reconocer que nos hacemos ejemplo prodigándonos, saliendo del encierro de nuestro egoísmo, del ser virtuosos para nosotros y por ende no sumando virtud a virtud para nosotros, sino sustrayéndonos siempre a nosotros en la renuncia en favor de otro, que es el único modo de crecer en la virtud y de multiplicarla. Al contrario, cuando queremos ser virtuosos para nosotros, la suma es desastrosamente sustracción: cuanto más acumulamos y más avaros somos de virtud, más sustraemos: es la virtud estéril, que esteriliza toda virtud. Una virtud tras la barricada, amurallada en el santuario de nuestra individualidad celosa de la propia virtud, es el cero de la virtud moral, porque ese santuario lo hemos erigido no para honrar en él la virtud, sino para honrarnos nosotros mismos. Sólo se es virtuoso prodigándose para que otro lo sea: y nada es más bellamente pródigo que el amor. No se mejoran los demás con las prédicas y elogiando nuestras virtudes, en este caso hechas miserables por la miseria de nuestro orgullo o de nuestra presunción, sino dando toda esa humanidad profunda y esencial que nos hace virtuosos en la ley del amor según el ser. Los hombres no han menester de portadores de férulas del alma helada por la virtud odiosa y estéril, alimento de orgullo insaciable e inexorable en la condenación, sino de luciérnagas que saben arder en el corazón, porque Dios las mueve dentro y las vuelve foco de amor: ejemplo para los demás y sobre todo de los demás; esto es del que todos pueden disponer y, disponiendo de él, enriquecerse con él, que es enriquecer el ejemplo mismo, que, en el sustraer para dar, crece en la virtud.

Donadora, la inteligencia moral es trascendentista y humanista; humanista en cuanto trascendentista y trascendentista en cuanto humanista. La razón ética es, en el fondo, quererlo todo para nosotros, para poseer; la inteligencia es, en cambio, quererlo todo para los demás, tener para dar. Implica, pues, una primera trascendencia que podemos llamar inherente a su misma naturaleza: salir fuera de sí para el otro, en cuanto que en este vínculo de persona a persona se hace uno mismo persona que se da y que recibe, la cual, a su vez, se hace persona dando. La cadena del amor abraza, no comprimiéndola, sino expandiéndola gozosamente, toda la humanidad; y esto es verdadero humanismo. Pero la difusividad del ser no tiene límites temporales y espaciales, ni humanos o históricos, esto es, no hay límite alguno que pueda inmanentizarla completamente y agotarla agotadoramente. La voluntas volunitatum surge siempre como condicionante de toda volición: a través del otro ser, conocido y querido en su ser, se quiere y se ama el Ser, el Ser sumo (Bien absoluto); y no puede no surgir, cualquiera que sea la presión que se ejerza contra ella, en cuanto que no hay nada en el orden humano o físico que pueda igualar la infinitud del pensar y del querer, esto es, el ser intuido en toda su extensión y querido en toda su plenitud. La dialéctica del espí- 
ritu aprieta al inmanentismo hasta ahogarlo: el hombre piensa en cuanto que está presente a su mente (y la constituye) la luz del ser en toda su infinitud; por eso el hombre piensa, conoce y quiere en cuanto intuye el ser infinito como posibilidad; así pues, todo conocimiento (de este o de aquel ente) y toda volición es posible por la luz del ser; pero siendo éste infinito, no hay conocimiento alguno, ni volición alguna que pueda agotar su capacidad, por lo que el pensar y el querer quedan siempre abiertos al pensamiento y a la volición del Ser absoluto. Por lo tanto, amando al otro en el orden del ser y en su ser se sigue que se lo ama en la presencia del ser infinito, interior a cada hombre como verdad primera; pero justo esta presencia empuja al hombre a no encerrarse en esta o aquella volición, imponiéndole el trascenderlas todas por amor del ser. La inteligencia moral es amor de todo ser en el orden del ser y en nombre del Ser, en nombre de Dios. Ella es, por su naturaleza, teísta, y como tal, trascendentista; y eminentemente humanista en cuanto que, por un lado, reconoce que el hombre o el ente pensante es primero en el orden de lo creado ( $y$ por tanto como fin), y por otro, en cuanto que lo abre a Dios con sólo ser auténticamente ella misma, le revela su situación ultraterrena, la posibilidad no suficiente de elevarse a un orden incomparablemente superior. En definitiva, la inteligencia moral es la voluntad de darlo todo a Dios a través del amor al prójimo; es querer, en este mundo y en el amor por toda cosa creada, para el otro mundo.

3. Solidaridad del pensamiento y de la vida. El punto en que se pone la mira, único para todo lo perseguido o querido, realiza la solidaridad de las fuerzas discordantes (para usar una expresión de Blondel), actualiza al hombre, como espíritu y como cuerpo, en su integridad y en su vocación fundamental. En efecto, sentir, pensar y querer en el orden del ser es sentir, pensar y querer en toda nuestra positividad de sujetos pensantes, cada hombre la suya y la de todos sus semejantes; y cada hombre la positividad de cada ente en su orden, que es su grado de ser. Es en esta positividad donde se forma, se desarrolla y crece la personalidad de cada persona según la lógica de sus aptitudes o vocaciones parciales, que no es exclusiva, sino inclusiva de todos los elementos, de modo que toda tendencia, aun aquellas que son modificadas, disciplinadas, corregidas y también descartadas, se emplee y no se inhiba, se incluya y no se suprima o reprima. Por consiguiente, la lógica de la vida espiritual no es lineal como la lógica puramente nocional -de los nexos y las relaciones en abstracto-, sino que se despliega, para decirlo con Blondel, sobre la diagonal del paralelógramo de todas las formas concurrentes y solidarias. Así es como ella, en cuanto lógica concreta, ya no de las ideas solamente pensadas, sino también vividas y por tanto encarnadas y actualizadas ( $y$ una idea vivida y encarnada adquiere una potencia céntuple y la capacidad unificativa de las demás), es lógica de vínculos entre entes reales, entre 
personas que queriéndose en el orden del ser y amándose como personas, se promueven tales, cada una en su peculiar e indeclinable personalidad. La lógica de la vida no procede, pues, por pura y simple deducción analítica, porque al trasformar las relaciones mentales en vínculos entre personas, implica la iniciativa y por ello la libertad, que es reveladora de algo nuevo, indeducible analíticamente. La libertad acarrea consecuencias nuevas: no la genera necesariamente ningún antecedente, por mucho que los antecedentes sean las condiciones de su libre ejercicio. Y la libertad se hace libre en la ley moral, en la presencia de la inteligencia en cada volición particular, que es volición de un ente conocido por la razón y querido por la voluntad; y la presencia de la inteligencia en la plenitud de su luz, que es presencia del ser, hace que cada acto de voluntad sea libre volición de la positividad que es cada cosa querida, pero siempre subordinadamente a la volición absoluta, la única esencial, que es la volición del Ser. Es en esta volición esencial y fundamental, que corresponde a la vocación esencial y fundamental del hombre en cuanto tal, donde encuentran orientación única y unidad directriz todas las voliciones particulares y las vocaciones parciales y se recuperan todos los elementos constitutivos del hombre, también los dispersivos y los negativos, de modo que nada esté totalmente ausente, ni del espíritu ni del cuerpo, y todo el hombre contribuye a la actualización de todo sí mismo, a su bien entero, también por medio de todo el mal que existe en él, que tanta es la potencia regeneratriz del espíritu que se actualiza a la luz de la verdad, en la voluntad del amor, en el corazón del ser, que es la vida de la vida, la verdad de la verdad, el amor del amor. Y el acto de amor es fundidor de los elementos más dispares y de las tendencias más contrarias, también de los instintos; y como fundidor, es trasformador, en cuanto que en el acto del fundir, trasforma los elementos, tendencias e instintos; es algo nuevo lo que nace, pero en donde todo se encuentra pacificado y armonizado. El pensamiento y la vida actualizan en este punto su solidaridad fundamental: el pensamiento da a la vida la orientación y la luz y la vida hace que el pensamiento se encarne en el acto mismo del vivir. La luz del ser enseña que cada ente es idéntico a sí mismo y es amado por aquello que es; y que es contradictorio quererlo por aquello que no es, a diferencia de su ser. Así el principio de identidad y el de no contradicción intervienen como principios de discernimiento, guía segura de la voluntad, disciplina interior, que es actualización de libertad, en cuanto es libre el acto de la voluntad que es conforme a la verdad de la inteligencia, esto es, no contradictorio. La lógica se vuelve lógica de la vida y la vida vida de la lógica: reconocer lo conocido es amarlo como se lo conoce. $\mathrm{Y}$ cuando se lo ama es siempre nuevo porque nuevo es cada acto de amor: se repite el conocer abstracto, lo puramente pensado; se renueva el conocer cuando es vivido, cuando es experiencia interior, que es irrepetible. Amar a un ente por lo que es, es amar siempre el mismo ente conocido, pero 
el acto de amarlo es siempre nuevo, es un conocerlo siempre más cada vez que se lo quiere.

La oposición entre la razón ética y la inteligencia moral, de que partimos, sobreentendía la profunda solidaridad y convergencia de ambas: no la abolición de la razón, sino el rehusarse a entenderla en la pura forma nocional, aislada de las demás formas de actividad espiritual y por ello abstracta y abstractizante; el rehusarse además a su absolutismo y autosuficiencia, que coincide con la absolutización de lo humano y de lo finito en general, entendido como totalidad del mundo y del conocer, porque también esto es depauperación de la razón y abstracción negativa de otras potencias del hombre, que lo impulsan a sobrepasar, con ayuda de la razón misma, su finitud y toda finitud. Nosotros rehusamos la inautenticidad de la razón, no la razón que razonablemente no se destierra, no se pone soberbiamente aparte, conoce que hay un saber más concreto, más unitivo y más pleno que el puramente racional, que hay una "sabiduría" que es más que la ciencia, sin excluir la ciencia misma. Nosotros no planteamos la alternativa "pensamiento discursivo" o "intuición", "razón" o "corazón", que es despedazar al hombre en dos operando una abstracción; al contrario, tendemos a la actualización del hombre entero, de la razón en el corazón y del corazón en la razón, de la discursividad en la intuición y de la intuición en la discursividad, de modo que a la luz infinita del ser intuido todo el hombre, en todas sus potencias y en la plenitud de su integridad, sea coextensivo a todo su ser. Nuestra "filosofía de la integridad" tiende a realizar un connubio indisoluble del pensamiento y de la vida, actualizado en el amor por todo ente en el orden del ser y en la vocación fundamental, de la inteligencia y de la voluntad volente, por el Ser, que es Persona absoluta hacia la que toda su naturaleza arrastra libremente al hombre. 